\title{
Cardiometabolic health, prescribed antipsychotics and health-related quality of life in people with schizophrenia-spectrum disorders: a cross-sectional study
}

\author{
Daniel Bressington ${ }^{1 *} \mathbb{D}$, Jolene Mui ${ }^{2}$, Mei Ling Tse ${ }^{1}$, Richard Gray ${ }^{3}$, Eric F. C. Cheung ${ }^{2}$ and Wai Tong Chien ${ }^{1}$
}

\begin{abstract}
Background: People with schizophrenia-spectrum disorders (SSD) often have high levels of obesity and poor cardiometabolic health. Certain types of antipsychotics have been shown to contribute towards weight gain and there is some equivocal evidence that obesity is related to poor health-related quality of life (HRQoL) in people with SSD. It is also still uncertain if antipsychotic polypharmacy/higher doses of antipsychotics are linked with HRQoL and/or increased risk of obesity/Cardiovascular Disease (CVD). Therefore, this study aimed to examine potential relationships between prescribed antipsychotic medication regimens, cardiometabolic health risks and HRQoL in community-based Chinese people with SSD.
\end{abstract}

Method: This cross-sectional study reports the results of baseline measurements of a random sample of patients in an ongoing controlled trial of physical health intervention for people with severe mental illness. Data from these randomly-selected participants $(n=82)$ were analysed to calculate 10-year CVD relative-risk (using QRISK ${ }^{\oplus}$ score), estimate the prevalence of metabolic syndrome and contextualize patients' prescribed antipsychotics (types, combinations and Daily Defined Dose equivalent). Patients self-reported their HRQoL (SF12v2) and their obesity condition was assessed by waist-circumference and Body Mass Index (BMI).

Results: Two-thirds of patients had a BMl $\geq 23 \mathrm{~kg} / \mathrm{m}^{2}$, almost half were centrally obese and $29 \%$ met the criteria for metabolic syndrome. The individual relative-risk of CVD ranged from 0.62 to 15 , and $13 \%$ had a moderate-to-high 10-year CVD risk score. Regression models showed that lower physical HRQoL was predicted by higher BMI and lower mental HRQoL. Higher Defined Daily Dose, clozapine, younger age and male gender were found to explain $40 \%$ of the variance in CVD relative risk.

Conclusion: The findings indicate that cardiometabolic health risks in people with SSD may be more common than those reported in the general Hong Kong population. The results also provide further support for the need to consider antipsychotic polypharmacy and higher doses of antipsychotics as factors that may contribute towards cardiometabolic risk in Chinese patients with SSD. Clinicians in Hong Kong should consider using routine CVD risk screening, and be aware that younger male patients who are taking clozapine and prescribed higher Defined Daily Dose seem to have the highest relative-risk of CVD.

Trial registration: Clinicaltrials.gov NCT02453217. Prospectively registered on $19^{\text {th }}$ May 2015.

Keywords: Schizophrenia, Cardiovascular disease risk, Cardiometabolic health, Antipsychotics, Polypharmacy, Defined Daily Dose, QRISK${ }^{\oplus}$, Obesity, Quality of life, SF-12

\footnotetext{
* Correspondence: dan.bressington@polyu.edu.hk

'School of Nursing, The Hong Kong Polytechnic University, Kowloon, Hong

Kong

Full list of author information is available at the end of the article
}

(c) The Author(s). 2016 Open Access This article is distributed under the terms of the Creative Commons Attribution 4.0 International License (http://creativecommons.org/licenses/by/4.0/), which permits unrestricted use, distribution, and reproduction in any medium, provided you give appropriate credit to the original author(s) and the source, provide a link to the Creative Commons license, and indicate if changes were made. The Creative Commons Public Domain Dedication waiver (http://creativecommons.org/publicdomain/zero/1.0/) applies to the data made available in this article, unless otherwise stated. 


\section{Background}

The poor cardiometabolic health state of people diagnosed with schizophrenia-spectrum disorders (SSD) and other severe mental illnesses (SMI) is a major clinical concern and a priority area for health services improvement worldwide [1-3]. It is now well recognised that compared with the general population people with SMI have a higher risk of developing obesity-related issues such as hypertension, stroke, metabolic syndrome (MES), and type-2 diabetes [4-8]. For example, it has been regularly reported that the risk of obesity in people with SMI is at least two times greater than in the general population [4].

In addition to obesity making a significant contribution towards the reduced life expectancy of people with SMI $[9,10]$, it may also negatively impact on patients' quality of life; studies conducted in the United States and Canada have shown that lower levels of physical health-related quality of life (HRQoL) in people with SSD are related to higher Body Mass Index (BMI) and waist circumference measurement [11-13]. Although physical HRQoL has been shown by some studies to be linked with obesity-related measures in SSD, a similar connection between mental HRQoL and body weight is not consistently reported in the literature [12, 14]. The relationship between MES and reduced HRQoL in people with SSD has also been investigated in Europe and the United States, with some studies reporting a significant association [15], whilst others identified no such connection [16].

Cardiovascular diseases are also commonly seen, and poorly treated in people with SSD. A meta-analysis involving 13 studies demonstrated that schizophrenia is associated with increased incidence of total cardiovascular disease (CVD), stroke, coronary heart disease (CHD) and congestive heart failure, with pooled relative-risks ranging from 1.2 to 1.81 [8]. The survival rates of SSD patients with $\mathrm{CHD}$ are lower than the general population with CHD; Harris and Barraclough [17] reported 90\% more deaths and Lahti et al. [18] reported a 2.9 relative risk of mortality when compared to people without a SMI who were diagnosed with CHD. Despite the increased prevalence of CVD, some studies have also shown that compared to the general population patients with SMI are less likely than to receive surgical interventions for CHD [19], have medications prescribed for CVD [20], and/or receive CVD risk screening tests [21].

The concerns about the increased prevalence of CVD in people with SSD have led to international calls for regular routine screening for CVD in this patient group $[2,22-25]$. In line with these recommendations, a number of structured CVD risk assessment tools are now used within health screening programmes for people with SMI $[1,26]$. The QRISK $^{\oplus} 2[27,28]$ and the Framingham coronary heart disease risk score [29] have both been used to measure CVD risk scores in this patient group in a variety of clinical settings [1,30]. Very few such studies have been conducted in Asian countries; one example is Tay, Nurjono and Lee [31] who used the Framingham risk score to determine the 10 year CVD risk of patients with SSD in Singapore. The results of this study demonstrated that the SSD participants had a mean 10 year CVD risk of $4.6 \%$ compared to $3.1 \%$ in the non-SSD comparison group. The $\mathrm{QRISK}^{\circ} 2$ tool is now increasingly used instead of the Framingham score [30] because it incorporates additional risk factors (for example, ethnicity, past history of smoking and family history of CVD). One UK study using the $\mathrm{QRISK}^{\oplus} 2$ found that patients with SMI in high-security inpatient forensic settings were more than twice-as-likely to have a high risk of CVD compared to people in the community without a SMI [28].

Numerous factors are likely to negatively influence the cardiometabolic health of people with SSD; including poor access to health services, unhealthy lifestyle behaviours, genetic predispositions and treatment-related issues $[4,32,33]$. Although the potential iatrogenic effects of treatment are only one factor that is likely to interact with a range of other influences on physical health, previous studies have consistently reported that antipsychotic medication is associated with increased risk for a range of cardiometabolic disorders [34, 35]. A large systematic review [36] also convincingly demonstrates that some antipsychotics are associated with at least twice the risk of MES, when compared with unmedicated people with SMI. Although individual antipsychotic medications are clearly associated (in varying degrees) with weight gain and type 2 diabetes [37], the relationships between the dosages, types and combined use (polypharmacy) of antipsychotic drugs and cardiometabolic health problems is not so clear. There is conflicting evidence from some cohort studies that the duration of exposure to antipsychotic medication, use of antipsychotic polypharmacy and higher antipsychotic dosages are linked to increased cardiovascular-related mortality in people with SSD [38-40]. A recent study conducted with Thai patients with SSD reported that BMI was significantly greater in patients prescribed antipsychotic polypharmacy as opposed to those prescribed monotherapy [41]. Nevertheless, it is still uncertain if a direct relationship exists between antipsychotic polypharmacy and weight gain in all patients with SSD [42, 43]; whereas systematic reviews have highlighted that antipsychotic polypharmacy is most likely to be associated with greater weight gain in younger people [5, 44].

There are very few studies conducted globally examining the potential relationships between cardiometabolic health risks, HRQoL and doses/combined use of prescribed antipsychotics. Therefore, the first objective of 
this study was to establish the level of CVD relative risk (using $\mathrm{QRISK}^{\circ} 2$ ) and prevalence of obesity (BMI and waist circumference) in community-based Chinese people prescribed antipsychotic medications for SSD. The second objective was to examine potential relationships between prescribed antipsychotic treatment/clinical characteristics, CVD risk levels, and HRQoL in the study participants.

\section{Methods}

\section{Design}

This observational, cross-sectional descriptive study reports the results of the baseline measurements of a random sample of patients $(n=82)$ participating in a randomised controlled trial of physical health intervention for Chinese people with severe mental illness. The ongoing trial was prospectively registered online at Clinicaltrials.gov (reference number NCT02453217). We report the current study in accordance with the Strengthening the Reporting of Observational Studies in Epidemiology (STROBE) guidelines [45]. The RCT was designed to test the effectiveness and acceptability of the Chinese Health Improvement Profile (CHIP) intervention compared to treatment as usual on patients' self-perceived physical well- being over a 12-month period. The RCT was necessary in order to robustly test the promising effects of the CHIP intervention observed in our earlier prospective case series study.

\section{Study setting}

The study was conducted in a Community Psychiatric Service (CPS) in the New Territories, the largest geographical region of Hong Kong SAR, China. The multidisciplinary community psychiatric team provided both crisis intervention and longer-term, recovery-focused community psychiatric services for people with different types of mental health problems.

\section{Ethical issues}

The study was approved by the Clinical Research Ethics Committee of Hospital Authority, Hong Kong and the Human Subjects Research Ethics Committee of The Hong Kong Polytechnic University prior to the start of the study. Patients were required to give written informed consent to take part in the study and for permission to access their medical records. The participants' information sheets clearly stated voluntary participation and rights of withdrawal from the study at any point without any negative treatment-related consequences.

\section{Recruitment and selection}

Patients were recruited for the ongoing cluster randomized controlled trial (RCT). The participant inclusion criteria for the RCT were patients aged 18-65 years with an ICD10 diagnosis of a SMI (schizophrenia and other related psychotic disorders, bipolar disorder, or major depression). A total of 510 patients with SMI were screened from the caseloads of 12 Community Mental Health Nurses (CMHNs). Potential participants $(n=155)$ were excluded if they were judged as being incapable of providing informed consent, currently an inpatient, or if they were diagnosed with co-morbidity of another chronic medical/or mental disorders such as learning disability, substance misuse disorders and organic brain diseases. A list of 15 eligible patients from each of the CMHNs caseloads was randomly generated using an external online randomization service (sealedenvelope.com); and they were approached until a minimum of 140 had agreed to take part. This minimum sample size was calculated for the RCT (assuming a medium-large effect size for the primary outcome measure, a significance level of 0.05 and a potential attrition rate of 30\%). A total of 23 patients (14\% of 165 approached) did not agree to participate and one patient was recruited but later found to be ineligible, resulting in 141 patients recruited into the RCT. We did not record the demographic or clinical characteristics of those patients who refused to participate, consequently we are unable to ascertain if they differed significantly from patients who agreed to take part.

For the current nested observational study, we analysed data from outpatients with any types of SSD who were aged 25-65 years and prescribed antipsychotic medication. We wanted to focus on patients with SSD in order to directly compare the findings with other SSD studies, and as the rates of CVD risk and obesity vary greatly in accordance with the type of SMI diagnosis we did not include data from patients with a diagnosis of bipolar disorder, and/or major depression. It was also necessary to exclude patients $<25$ years old in order to improve the predictability of $\mathrm{QRISK}^{\circ} 2$ scores (the minimum age that can be entered into the QRISK $^{\circ} 2$ calculator is 25 and therefore the algorithm would underestimate the relative risk of patients aged $<25$ years). Subsequently, 59 patients were excluded as ineligible due to age, diagnosis, or not being prescribed antipsychotics; resulting in a final sample of 82 participants.

\section{Data collection procedures and measures}

The 12 CMHNs undertook data collection as baseline measurements for the cluster RCT either in the CPS clinic or at patients' homes. All recruitment and baseline measurements were completed before the randomisation of the CMHNs into the intervention or treatment-as-usual group. Data were collected from July to September 2015. 


\section{Demographic and clinical information}

The CHMNs recorded patients' height, weight, BMI, waist circumference measurement, heart rate (radial pulse), and blood pressure. Blood pressure was recorded using a digital sphygmomanometer whilst participants were in a seating position, weight was measured using a digital scale and a digital stadiometer was used to measure height. The CMHNs were instructed to record waist circumference whilst patients were stood in a relaxed position using a measuring tape placed snugly across the midpoint between the lower rib and the top of the iliac crest at a level parallel to the floor. In addition, all recent ( $\leq 1$ year) clinical data relating to the physical state of participants (i.e. temperature, respiration rate, urine tests, fasting blood glucose levels, lipid/cholesterol levels, liver function tests and serum prolactin levels) that were routinely recorded as part of standard practice in the electronic patient records system were also examined and recorded. Prevalence of obesity was calculated with gender/ethnicity specific waist circumference measurements and the BMI $\left(\mathrm{kg} / \mathrm{m}^{2}\right)$. Data relating to smoking status, presence of rheumatoid arthritis, diabetes, heart and kidney diseases, and family history of CVD were obtained from the patients or their medical records.

\section{Prescribed antipsychotic treatment}

Types of antipsychotics, dosage and formulations currently prescribed to patients were recorded by the CHMNs from the information in the medical records/ prescription charts. To facilitate the direct comparison across patients on different antipsychotics and identify/ examine the relationship between the dosages and the CVD risk/obesity, a standardized and reliable unit of dosage measurement was necessary (i.e. the Defined Daily Dose (DDD) [46]. The system of DDD is defined as "the assumed average maintenance dose per day for a drug used for its main indication in adults" and is recommended as an international standard for drug utilization studies by the World Health Organization [47]. A global average is assigned as the single DDD for each drug and route of administration. For long-acting injections, the DDDs are based on the average recommended doses divided by the dosing interval. Prescribed dosages of antipsychotics for patients was converted into multiples of the Defined Daily Dose (DDD) for each individual antipsychotic by dividing the prescribed daily dose by the DDD. For patients on more than one antipsychotic, the multiples of DDD for each drug were summed up to give a cumulative dosage measurement.

\section{Cardiovascular risk scores}

The version 2 of $\mathrm{QRISK}^{\bullet}\left(\mathrm{QRISK}^{\circ} 2-2015\right)$ [27, 28] was used to calculate the 10-year CVD risk score of each participant. The QRISK $^{\circ} 2$ score and an associated individual CVD relative risk (relative to a person of the same age, sex and ethnicity without clinical indicators of risk and a cholesterol ratio of 4.0, systolic blood pressure of 125 and an ethnicity-specific healthy BMI) were estimated by entering a number of factors into the online QRISK $^{\circ} 2$-2015 calculation tool (https://qrisk.org/2015/). These factors included: age, sex, ethnicity, height, weight, smoking status, systolic blood pressure, cholesterol/high-density lipoprotein (HDL) ratio, hypertension treatment, presence of rheumatoid arthritis, diabetes, heart and kidney diseases, and family history of CVD. The test results recorded closest in time to the anthropometric measures were used to calculate cardiovascular risk scores. Where test results were unavailable, or more than 1-year-old, the values were left blank and missing items were automatically imputed by the QRISK $^{\circ} 2$ calculator with predicted values based on the patient's ethnicity, age and sex. The QRISK ${ }^{\circ} 2$ algorithm was developed from the QResearch medical database of 2 million patients collected at 550 general practices in UK from 1993 to 2008 and is updated annually to reflect the actual changes of the population. Compared to Framingham score, the equation of $\mathrm{QRISK}^{\circ} 2$ was derived from more recent and diverse ethnic groups (and the derivative cohort consisted of almost 20,000 people of Chinese ethnicity). It was also based on a larger variety of data (having additional data on ethnicity, family medical history, socio-economic status, and other clinical factors). The predictability of QRISK $^{\circ} 2$ was validated in samples of the QResearch database [27] and external data sources $[48,49]$ and compared with the corresponding Framingham scores. The results showed QRISK $^{\circ} 2$ outperformed Framingham score in respect to discrimination $\left(\mathrm{QRISK}^{\circ} 2\right.$ predicted $38 \%$ of the variation in men and $43 \%$ in women compared with Framingham's 35 and 39\% respectively). In 2010 the UK's National Institute for Health and Care Excellence guidelines stated that the Framingham risk algorithm should not be used for CVD risk assessment unless it was considered together with other approaches (such as QRISK ${ }^{\circ}$ ) [50], and the UK's Royal College of Psychiatrists now suggest to use the $\mathrm{QRISK}^{\circ} 2$ to estimate CVD risk in people with SSD [1].

\section{Prevalence of metabolic syndrome (MES)}

The consensus criteria of metabolic syndrome (MES) for Chinese populations from the International Diabetes Federation (IDF) [36] were used. Three out of five parameters, including central obesity (waist circumference of $\geq 80 \mathrm{~cm}$ for females and $\geq 90 \mathrm{~cm}$ for males) plus two additional ones from the following four aspects, including: raised blood pressure (systolic $\mathrm{BP} \geq 130$ or diastolic $\mathrm{BP} \geq 85 \mathrm{~mm} / \mathrm{Hg}$ ), reduced HDL $(<1.03 \mathrm{mmol} / \mathrm{L}$ in males, $<1.29 \mathrm{mmol} / \mathrm{L}$ in females), raised triglycerides $(\geq 1.7 \mathrm{mmol} / \mathrm{L})$ and elevated 
fasting plasma glucose $(\geq 5.6 \mathrm{mmol} / \mathrm{L})$, were used to define the presence of MES in the participants.

\section{Health-related quality of life}

Patients self-reported their perceived HRQoL using the widely used and well-established 12-Item Short Form Survey 2nd version (SF12v2). Physical HRQoL was calculated using the physical component subscale (PCS) and mental HRQoL with the mental component subscale (MCS). The SF12v2 was developed by Ware, Kosinski, and Dewey [51] as a shorter version of the previous SF36 [52]. The Hong Kong Chinese version of the SF12v2 demonstrated good test-retest reliability and internal consistency (intraclass correlation 0.82; Cronbach's alpha 0.67) for a Chinese adult population [53].

\section{Data analysis strategy}

$\mathrm{IBM}^{\circ} \mathrm{SPSS}^{\circ}$ software version 21 for Windows ${ }^{\bullet}$ was used for all analyses. The clinical characteristics, prescribed antipsychotic medication, prevalence of obesity and metabolic diseases, cardiometabolic risk levels, and HRQoL among the participants were summarised by descriptive statistics. Relationships between these above and the other health parameters were explored by correlation and tests of between group differences. Parametric (i.e. independent sample $\mathrm{T}$ (two-tailed) or ANOVA) and non-parametric (i.e. Mann-Whitney U or Kruskal-Wallis) tests were used to examine the differences in BMI/waist circumference, QRISK $^{\circ} 2$ score/ CVD relative risk, and HRQoL scores across different antipsychotic medication usage groups in terms of their: number of types of antipsychotics (1-3), antipsychotic polypharmacy (yes/no,) antipsychotic combinations (first generation, second generation, first and second generation, long-acting intramuscular injection, oral, and both oral and long acting intramuscular injection), and Clozapine and DDD ranges. Multiple step-wise linear regression analyses were performed to identify which of the statistically significant treatmentrelated and clinical/patient-related variables could satisfactorily explain the variance in physical HRQoL and CVD relative risk. The level of significance was set at $p<.05$ for all tests.

\section{Results}

\section{Demographic and clinical characteristics}

The demographic and clinical characteristics of participants are summarised in Table 1.

Data from a total of 82 participants with a mean age of 49 years $(\mathrm{SD}=8.57$, range $30-65$ ) were analysed. Nearly $90 \%$ of the patients were diagnosed with schizophrenia for more than 10 years and had an average of 4 hospital admissions. In spite of the relatively high prevalence of metabolic syndrome (29\%), very few were receiving diabetes (8.5\%) or cholesterol treatments (3.7\%). Around one-third were on antihypertensive medication $(n=25)$, however only seven were diagnosed with hypertension, with the majority $(n=18)$ being prescribed propranolol for controlling anxiety or extrapyramidal side effects. A total of 28 patients (34\%) were current smokers.

About one-third of the patients were prescribed more than one type of antipsychotic (antipsychotic polypharmacy). Most were on second-generation antipsychotics (SGA); however, about $15 \%$ were on both first-generation antipsychotics (FGA) and SGA. Over one-third were prescribed long-acting intramuscular injections (LAI), and around a quarter was taking both LAIs and oral formulations. According to the Defined Daily Dose (DDD) suggested by the World Health Organisation, $61 \%$ of patients were prescribed antipsychotics in excess of the recommended adult DDD (>1.0 cumulative DDD).

\section{Cardiometabolic health \& health-related quality of life}

The cardiometabolic health risks and HRQoL scores of participants are presented in Table 1. Cardiometabolic health risks were observed to be very common; over two-thirds were found to have an unhealthy BMI $(\geq 23$ $\mathrm{kgm}^{2}$ ), nearly half were obese in terms of both BMI and waist circumference, and $29 \%$ met the IDF criteria of metabolic syndrome. In terms of QRISK 2 scores, certain participants (13\%) showed a moderate-to-high CVD risk score $(\geq 10 \%)$; whereas, the overall 10 -year CVD individual relative risk was high with a mean of $2.8(\mathrm{SD}=2.96)$ and median of $1.8(\mathrm{IQR}=1.87)$. Nevertheless, there was a wide range of 10 year CVD relative risk (between 0.62 and 15) among the patients.

\section{Relationships between demographic/clinical characteristics, cardiometabolic health risks and HRQoL}

The correlations between demographic/clinical characteristics, cardiometabolic health and HRQoL are presented in Table 2. Factors significantly related to BMI included a weak negative correlation with age $(p=.045)$ and weak positive correlation with number of previous admissions $(p=.015)$. Age was also negatively correlated with CVD relative risk level $(p<.001)$. Waist circumference measurement was positively correlated number of previous hospital admissions $(p<.001)$. The two SF12v2 subscale scores were correlated to each other $(p=.006)$ and increased BMI was negatively correlated with PCS $(p=.032)$. No other significant correlations were found between demographic/ clinical characteristics, cardiometabolic health risks and HRQoL. 
Table 1 Demographic, clinical and treatment characteristics of study participants $(N=82)$

\begin{tabular}{|c|c|}
\hline \multicolumn{2}{|l|}{ Demographics } \\
\hline Male - N (\%) & $49(59.8)$ \\
\hline Female & $33(40.2)$ \\
\hline Age in years - Mean (SD), range & 48.67 (8.57), 30-65 \\
\hline $\begin{array}{l}\text { Duration of illness in months - Mean (SD), } \\
\text { range }\end{array}$ & $204.03(138.12), 4-720$ \\
\hline $\begin{array}{l}\text { Numbers of previous psychiatric admissions } \\
\text {-Mean (SD), range }\end{array}$ & $3.97(4.17), 0-20$ \\
\hline \multicolumn{2}{|l|}{ Marital Status - N (\%) } \\
\hline Single & $33(40.2)$ \\
\hline Married & $28(34.1)$ \\
\hline Divorced & $11(13.4)$ \\
\hline Other & $10(12.3)$ \\
\hline \multicolumn{2}{|l|}{ Educational Level - N (\%) } \\
\hline Primary & $26(31.7)$ \\
\hline Secondary & $44(53.7)$ \\
\hline University/college & $9(11.0)$ \\
\hline None/other & $3(3.6)$ \\
\hline \multicolumn{2}{|l|}{ Employment Status - N (\%) } \\
\hline Full time & $19(23.2)$ \\
\hline Part time & $5(6.1)$ \\
\hline Unemployed & $40(48.8)$ \\
\hline Other & $18(22.0)$ \\
\hline \multicolumn{2}{|l|}{ Psychiatric Diagnosis - N (\%) } \\
\hline Schizophrenia & $40(48.8)$ \\
\hline Paranoid schizophrenia & $33(40.2)$ \\
\hline $\begin{array}{l}\text { Other psychosis (including } \\
\text { schizoaffective/delusional disorder, } \\
\text { psychosis NOS) }\end{array}$ & $9(11.0)$ \\
\hline \multicolumn{2}{|l|}{ Smoking status - N (\%) } \\
\hline Non smoker & $50(61.0)$ \\
\hline Ex-smoker & $1(1.2)$ \\
\hline Light smoker (<10 per day) & $5(6.1)$ \\
\hline Moderate smoker (10-19 per day) & $11(13.4)$ \\
\hline Heavy smoker ( $\geq 20$ per day) & $15(18.3)$ \\
\hline \multicolumn{2}{|l|}{ Medication Treatment - N (\%) } \\
\hline Prescribed an antihypertensive & $25(30.5)$ \\
\hline Prescribed a statin & $3(3.7)$ \\
\hline Prescribed diabetes treatment & $7(8.5)$ \\
\hline Prescribed antipsychotic polypharmacy & $28(34.1)$ \\
\hline \multicolumn{2}{|l|}{ Number of Antipsychotics Prescribed - N (\%) } \\
\hline 1 & $54(65.9)$ \\
\hline 2 & $24(29.3)$ \\
\hline 3 & $4(4.9)$ \\
\hline \multicolumn{2}{|l|}{ Prescribed psychotropic medications - N (\%) } \\
\hline First Generation Antipsychotics & $35(42.7)$ \\
\hline
\end{tabular}

Table 1 Demographic, clinical and treatment characteristics of study participants $(N=82)$ (Continued)

\begin{tabular}{|c|c|}
\hline Second Generation Antipsychotics (all types) & $60(73.2)$ \\
\hline Olanzapine & $16(19.5)$ \\
\hline Risperidone & $9(11.0)$ \\
\hline Paliperidone & $9(11.0)$ \\
\hline Quetiapine & $7(8.5)$ \\
\hline Amisulpride & $4(4.9)$ \\
\hline Aripiprazole & $2(2.4)$ \\
\hline Clozapine & $14(17.1)$ \\
\hline Clozapine and another antipsychotic & $5(6.1)$ \\
\hline First and Second Generation Antipsychotics & $12(14.6)$ \\
\hline $\begin{array}{l}\text { Long acting intramuscular antipsychotic } \\
\text { injection }\end{array}$ & $31(37.8)$ \\
\hline $\begin{array}{l}\text { Oral antipsychotic and long acting } \\
\text { intramuscular injection }\end{array}$ & $19(23.2)$ \\
\hline Mood stabilizer/anti-manic drugs & \\
\hline Lithium & $3(3.7)$ \\
\hline Sodium valproate & $7(8.5)$ \\
\hline SSRI antidepressant & $2(2.4)$ \\
\hline Prescribed Dosage of Antipsychotics & \\
\hline $\begin{array}{l}\text { Cumulative multiples of DDD - Mean (SD), } \\
\text { range }\end{array}$ & $1.62(1.08), 0.1-5.14$ \\
\hline$\leq 1.0 \mathrm{DDD}-\mathrm{N}(\%)$ & $32(39.0)$ \\
\hline 1.1-2.0 DDD - N (\%) & $26(31.7)$ \\
\hline$>2.0 \mathrm{DDD}-\mathrm{N}(\%)$ & $24(29.3)$ \\
\hline Cardiometabolic Health & \\
\hline BMI $\left(\mathrm{kg} / \mathrm{m}^{2}\right)$ - Mean (SD) & $24.81(3.73)$ \\
\hline BMI underweight - N (\%) & $3(3.7)$ \\
\hline BMI healthy - N (\%) & $22(26.8)$ \\
\hline BMI overweight - N (\%) & $18(22.0)$ \\
\hline BMI obese I - N (\%) & $33(40.2)$ \\
\hline BMI obese II - N (\%) & $5(6.1)$ \\
\hline $\begin{array}{l}\text { Waist circumference obese }(\geq 80 \mathrm{~cm} \\
\text { females, } \geq 90 \mathrm{~cm} \text { males) }-\mathrm{N}(\%)\end{array}$ & $40(48.8)$ \\
\hline $\begin{array}{l}\text { Metabolic syndrome (meets IDF criteria) } \\
-\mathrm{N}(\%)\end{array}$ & $24(29.3)$ \\
\hline QRISK ${ }^{\oplus 2}$ 10-year CVD risk score - Mean (SD) & $5.28(5.45)$ \\
\hline$<10 \%$ CVD risk score (low) - N (\%) & $71(86.6)$ \\
\hline 10-19.9\% CVD risk score (moderate) - N (\%) & $9(11.0)$ \\
\hline $20 \%+C V D$ risk score (high) $-\mathrm{N}(\%)$ & $2(2.4)$ \\
\hline 10-year CVD relative risk - Mean (SD) & $2.80(2.96)$ \\
\hline - Median (IQR) & $1.80(1.87)$ \\
\hline Health-Related Quality of Life & \\
\hline Physical component score (PCS) - Mean (SD) & $46.01(7.11)$ \\
\hline Mental component score (MCS) - Mean (SD) & $46.93(9.59)$ \\
\hline
\end{tabular}

$B M I$ body mass index, CVD cardiovascular disease, $D D D$ daily defined dose, IDF international diabetes federation, SD standard deviation, NOS not otherwise specified 
Table 2 Demographic and clinical characteristics correlated with body mass index, waist circumference, relative risk of cardiovascular disease, HRQoL summary subscales and diastolic blood pressure

\begin{tabular}{lllllll}
\hline & BMl & Waist circumference & CVD relative risk & PCS & MCS & Diastolic blood pressure \\
\hline $\begin{array}{l}\text { Age in years } \\
(n=80-82)\end{array}$ & $\mathrm{a}_{-} .220, .049^{*}$ & $\mathrm{a}-.112, .315$ & $-.386,<.001^{* * *}$ & $-.183, .099$ & $.123, .269$ & $.116, .299$ \\
$\begin{array}{l}\text { Number of previous psychiatric admissions } \\
(n=77-78)\end{array}$ & $.276, .015^{*}$ & $.386, .001^{* * *}$ & $.165, .149$ & $-.182, .111$ & $-.136, .236$ & $.209, .067$ \\
$\begin{array}{l}\text { Number of antipsychotic types } \\
(n=81-82)\end{array}$ & $.330, .003^{* *}$ & $.171, .124$ & $.270, .014^{*}$ & $-.123, .270$ & $-.138, .217$ & $.180, .106$ \\
$\begin{array}{l}\text { Dosage of antipsychotics (DDD) } \\
(n=81-82)\end{array}$ & $.257, .021^{*}$ & $.214, .054$ & $.361, .001^{* *}$ & $-.149, .182$ & $-.092, .413$ & $.244, .027^{*}$ \\
$\begin{array}{l}\text { PCS } \\
(n=81-82)\end{array}$ & $-.239, .032^{*}$ & $-.118, .291$ & $-.005, .967$ & - & $.299, .006^{* *}$ & $-.047, .678$ \\
$\begin{array}{l}\text { MCS } \\
(n=81-82)\end{array}$ & $.093, .409$ & $.118, .289$ & $.030, .789$ & $.299, .006^{* *}$ & - & $.077, .492$ \\
\hline
\end{tabular}

$B M I$ body mass index, $C V D$ cardiovascular disease, $D D D$ daily defined dose, $M C S$ mental component score, $P C S$ physical component score Variables in the table are Spearman's rho $\left(r_{s}\right)$ or ${ }^{\text {a Pearson's } r}(r)$, followed by $p$-value

${ }^{*} p<.05,{ }^{* *} p<.01,{ }^{* * *} p<.001$

Relationships between prescribed antipsychotics, HRQoL and cardiometabolic health risks

The main correlations between prescribed antipsychotics, cardiometabolic health and HRQoL are shown in Table 2. Greater numbers of types of prescribed antipsychotics were significantly positively correlated with increased BMI $(p=.003)$ and elevated 10-year CVD relative-risk $(p=.014)$. Cumulative DDD was positively correlated with BMI $(p=.021)$, CVD relative risk $(p=.001)$ and diastolic blood pressure $(p=.027)$. There were no other significant correlations identified between prescribed antipsychotics, cardiometabolic health risks and HRQoL.

\section{Differences in HRQoL across demographic/clinical characteristic groups and antipsychotic treatment regimens}

Females had a higher MCS scores than males $(Z=-2.30$, $p=.022$ ) with mean ranks of 36.54 (male) and 48.86 (female), but a significant gender difference was not observed in the PCS scores. No significant relationships were identified between HRQoL and any other demographic/clinical characteristic or antipsychotic treatment groups.

\section{Differences in cardiometabolic health across demographic/clinical characteristic groups}

Table 3 shows the differences in cardiometabolic health and HRQoL across demographic and clinical characteristic groups. The presence of MES was only associated with higher number of previous admissions (mean ranks $=44.37$ vs $32.81, p=.027$ ) but not any other demographic factor and clinical characteristic. Males had a greater CVD relative risk than females $(p<.001)$.
Differences in cardiometabolic health risks across antipsychotic treatment groups

Table 3 provides details of the test results for differences in cardiometabolic health between antipsychotic treatment groups.

\section{BMI and central obesity}

Patients prescribed a combination of oral and LAIs had a greater BMI than participants prescribed medications via a singular route of administration $(p=.008)$. Patients prescribed a combination of both FGA and SGA also had a higher BMI compared to those on a single class of antipsychotic medication $(p=.009)$. Bonferroni-corrected post-hoc tests of one-way ANOVA analysis revealed that patients prescribed with three different antipsychotic drugs had a significantly higher BMI than those prescribed with only one type, with a mean difference of $5.25 \mathrm{~kg} / \mathrm{m}^{2}$ $(p=.010)$.

A significant result of the ANOVA test revealed that patients prescribed with a dosage of $>2.0$ DDD had significantly higher BMI than those with dosages of 1.1-2.0 DDD or $\leq 1.0$ DDD in the Bonferroni posthoc test $(p=.001$ and $p=.011$ respectively). Higher multiples of DDD (>2.0 DDD) was also significantly associated with higher waist circumference compared to lower dosage (1.1-2.0 DDD) with a mean difference of $9.73 \mathrm{~cm}(p-.007)$ in Bonferroni post-hoc test.

\section{Blood pressure and pulse}

Kruskal-Wallis test showed significant differences of diastolic blood pressure across dosage groups, $p=.021$ ); Mann-Whitney U-tests indicate that difference between $>2.0$ DDD and $\leq 1.0$ DDD groups was significant $(Z=-2.61, p=.009$, mean ranks of 35.02 vs 23.61). Patients prescribed clozapine had a higher diastolic blood pressure than those prescribed other 
Table 3 Differences in cardiometabolic health risk indicators across gender and antipsychotic treatment groups

\begin{tabular}{|c|c|c|c|c|c|c|c|c|c|c|c|c|c|c|c|c|c|}
\hline & \multicolumn{4}{|c|}{$\mathrm{BMI}\left(\mathrm{kg} / \mathrm{m}^{2}\right)$} & \multicolumn{4}{|c|}{ Waist circumference $(\mathrm{cm})$} & \multicolumn{3}{|c|}{ Diastolic blood pressure } & \multicolumn{3}{|l|}{ Pulse } & \multicolumn{3}{|l|}{ CVD relative risk } \\
\hline & $\overline{M D^{a}}$ & {$[95 \% \mathrm{Cl}]$} & $T$ & $p$ & $\overline{M D^{a}}$ & {$[95 \% \mathrm{Cl}]$} & $T$ & $p$ & $\mathrm{MR}^{\mathrm{b}}$ & $z$ & $p$ & $\overline{M R^{b}}$ & $z$ & $p$ & $M R^{b}$ & $z$ & $p$ \\
\hline \multirow[t]{2}{*}{ Gender } & 1.21 & {$[0.46,2.88]$} & 1.44 & .154 & 3.25 & {$[-1.84,8.34]$} & 1.27 & .208 & 46.24 (male) & -2.22 & $.027^{*}$ & 44.76 (male) & -1.15 & .130 & 49.32 (male) & -3.62 & $<.001^{* * *}$ \\
\hline & & & & & & & & & 34.45 (female) & & & 36.67 (female) & & & 29.89 (female) & & \\
\hline \multirow{2}{*}{$\begin{array}{l}\text { Clozapine prescribed } \\
\text { (yes Vs no) }\end{array}$} & 0.85 & {$[-1.41,3.11]$} & 0.75 & .456 & 3.07 & {$[-3.60,9.74]$} & 0.92 & .363 & 41.52 (no) & -0.02 & .985 & 56.04 (yes) & -2.52 & $.012^{*}$ & 55.71 (yes) & -2.45 & $.014^{*}$ \\
\hline & & & & & & & & & 41.39 (yes) & & & 38.51 (no) & & & 8.57 (no) & & \\
\hline \multirow{2}{*}{$\begin{array}{l}\text { Oral and LAI } \\
\text { (combination Vs single route) }\end{array}$} & 2.58 & {$[0.71,4.46]$} & 2.74 & $.008^{* *}$ & 4.30 & {$[-1.60,10.20]$} & 1.45 & .151 & 50.82 (combine) & -1.96 & .050 & 42.46 (single) & -0.67 & .505 & 53.68 (combine) & -2.54 & $.011^{*}$ \\
\hline & & & & & & & & & 38.69 (single) & & & 38.32 (combined) & & & 37.83 (single) & & \\
\hline \multirow{3}{*}{$\begin{array}{l}1^{\text {st }} \text { and } 2^{\text {nd }} \text { generation } \\
\text { antipsychotics } \\
\text { (combination Vs single class) }\end{array}$} & 3.01 & {$[0.77,5.25]$} & 2.67 & $.009^{* *}$ & 2.98 & {$[-4.13,10.9]$} & 0.83 & .407 & 49.54 (combine) & -1.28 & .202 & 42.20 (single) & -0.65 & .519 & 59.50 (combine) & -2.83 & $.005^{* *}$ \\
\hline & & & & & & & & & 40.12 (single) & & & 37.42 (combine) & & & 38.41 (single) & & \\
\hline & $M D^{c}$ & {$[95 \% \mathrm{Cl}]$} & $F$ & $p$ & $\mathrm{MD}^{c}$ & {$[95 \% \mathrm{Cl}]$} & $F$ & $p$ & $\mathrm{MR}^{\mathrm{d}}$ & $H$ & $p$ & $M R^{d}$ & $H$ & $p$ & $M R^{d}$ & $H$ & $p$ \\
\hline \multirow{3}{*}{$\begin{array}{l}\text { Number of antipsychotic } \\
\text { types } \\
\text { (one, two, three) }\end{array}$} & 5.25 & {$[0.73,9.77]$} & 4.93 & $.010^{*}$ & 5.43 & {$[-9.13,19.98]$} & 0.47 & 1.000 & 49.44 (two) & 3.83 & .147 & 43.45 (one) & 1.14 & .564 & 37.19 (one) & 6.71 & $.035^{*}$ \\
\hline & lone $\mathrm{V}$ & s three) & & & lone, & two, three) & & & 38.50 (three) & & & 38.23 (two) & & & 47.52 (two) & & \\
\hline & & & & & & & & & 38.19 (one) & & & 34.75 (three) & & & 63.50 (three) & & \\
\hline \multirow{4}{*}{$\begin{array}{l}\text { Dosage of prescribed } \\
\text { antipsychotics } \\
\text { (>2 DDD, 1.1-2 DDD, } \\
\leq 1 \text { DDD) }\end{array}$} & 3.94 & {$[1.57,6.30]$} & 8.73 & $.001^{* * *}$ & 9.73 & {$[2.22,17.24]$} & 5.28 & $.007^{* *}$ & $49.90(>2)$ & 7.77 & $.021^{*}$ & $42.66(\leq 1)$ & 0.13 & .940 & $52.04(>2)$ & 9.41 & $.009^{* *}$ \\
\hline & $(>2$ vs & $1.1-2)$ & & & $(>2 \mathrm{vs}$ & $5.1-2)$ & & & $44.44(1.1-2)$ & & & $40.81(>2)$ & & & $42.90(1.1-2)$ & & \\
\hline & 2.79 & {$[0.52,5.06]$} & 8.73 & $.011^{*}$ & & & & & $32.81(\leq 1)$ & & & $40.71(1.1-2)$ & & & $32.45(\leq 1)$ & & \\
\hline & $(>2 \mathrm{vs}$ & $\leq 1)$ & & & & & & & & & & & & & & & \\
\hline
\end{tabular}

$C I$ confidence interval, $M D$ mean difference, $M R$ mean rank, $B M I$ body mass index, $C V D$ cardiovascular disease, $D D D$ daily defined dose, $L A l$ long acting intramuscular injection

${ }^{\mathrm{a}}$ Independent sample T-test, ${ }^{\mathrm{b}}$ Mann-Whitney U-test, ${ }^{\mathrm{c}}$-way ANOVA (Bonferroni-corrected post-hoc test), ${ }^{\mathrm{d} K r u s k a l-W a l l i s}$ test

$* p<.05, * * 0<.01, * * * 0<.001$ 
antipsychotics $(p=.012)$. Mann-Whitney U-tests of individual types of antipsychotics revealed a higher pulse rate for male patients than females $(p=.027)$. No other significant differences were found in blood pressure and pulse across gender or antipsychotic treatment groups.

\section{CVD relative risk}

Patients prescribed a combination of oral antipsychotics and long acting intramuscular antipsychotic injections had a greater CVD relative-risk than those patients given antipsychotics via a singular route of administration $(p=.011)$. Similarly, patients prescribed a combination of both FGA and SGA also had a higher CVD relative risk than those prescribed monotherapy $(p=.005)$. Patients taking clozapine were found to have a greater CVD relative risk than those who were not prescribed clozapine $(p=.014)$.

Kruskal-Wallis test of CVD relative risk across the antipsychotic dosage groups showed the differences were significant in patients prescribed with dosages over the WHO recommended DDD $(p=.009)$. Mann-Whitney Utests indicated that the risks of $>2.0$ DDD and $\leq 1.0$ DDD groups were significantly different $(\mathrm{Z}=-3.20, p=.001)$ with mean ranks of 36.54 and 22.47 respectively. Significant differences in CVD relative risk across number of antipsychotic types were also found using Kruskal-Wallis test $(p=.035)$; Mann-Whitney $U$-test showed that the CVD relative risk of one type of antipsychotic (mean rank $=28.2$ ) is significantly less from that of three types (mean rank $=47.0, Z=-2.15, p=.032$ ).

\section{Regression analysis of physical HRQoL and CVD relative-risk}

Stepwise linear regression analysis was performed to assess the associations of BMI and MCS with PCS subscale (of HRQoL) scores. Collinearity test confirmed the independency of BMI and MCS (tolerance $=.992$, VIF $=$ 1.008) and assumption of independent errors of residuals was met (Durbin-Watson value $=1.574$ ). Standard residual plots showed that the data contained no outliers and met the criteria of normality. The model $(F(2$, $78)=5.03, p=.009)$ with $\mathrm{R}^{2}$ of .114 and adjusted $\mathrm{R}^{2}$ of .091 showed that both BMI and MCS were significant predictors. Beta-coefficients and $p$-values are shown in Table 4.

Another stepwise linear regression was conducted to explore the significant predictors of CVD relative risk. The relative risk was studied instead of QRISK $^{\circ} 2$ score because it was age, sex and ethnicity controlled and this could provide more accurate results. Given the ratio nature of the CVD relative risk variable and non-normal distribution, we used transformed log-normal scores in the stepwise linear regression. Explanatory treatment
Table 4 Results from multiple regression models: A) Physical health-related quality of life (HRQoL) regressed on body mass index and mental HRQOL. B) Relative risk of cardiovascular disease regressed on age, gender, clozapine medication and antipsychotic dosage

\begin{tabular}{llllll}
\hline & $b$ & SE & Beta & $p$ & Adjusted $R^{2}$ \\
\hline A) PCS regressed on: & & & & & \\
BMI $\left(\mathrm{kg} / \mathrm{m}^{2}\right)$ & -0.516 & 0.203 & -0.272 & .013 & \\
MCS & 0.167 & 0.079 & 0.226 & .038 & \\
Constant & 50.918 & 6.025 & & $<.001$ & \\
& & & & & .091 \\
& & & & & $(p=.009)$
\end{tabular}

B) CVD relative risk regressed on:

$\begin{array}{lllll}\text { Prescribed DDD } & 0.198 & 0.063 & 0.283 & .002 \\ \text { On clozapine } & 0.523 & 0.175 & 0.263 & .004 \\ \text { Age (years) } & -0.030 & 0.008 & -0.346 & <.001 \\ \text { Gender (male=1) } & -0.364 & 0.138 & -0.238 & .010 \\ \text { Constant } & 1.751 & 0.515 & & .001\end{array}$

$b$ unstandardized regression coefficient, Beta standardized regression coefficient, SE standard error, BMI body mass index, CVD cardiovascular disease, $D D D$ daily defined dose, MCS mental component score, $P C S$ physical component score

variables that were found to be significantly associated with CVD relative risk (including multiples of DDD, number of antipsychotic types, combinations of oral and LAI, combinations of FGA and SGA, clozapine prescription) and possible demographic variables (age and gender) were entered into the model. Collinearity tests indicated that the VIF of these seven variables were all $<5$ and thus multi-collinearity was not a concern. A significant model including age, gender, DDD and clozapine were found to explain $39.9 \%$ of the variance in CVD relative risk (adjusted $\mathrm{R}^{2}=.399, F(4$, $77)=14.45, p<.001)$. Table 4 summarizes the details of beta-coefficients of each contributing variable. Analysis of residuals confirmed the data contained no outliers and assumption of independent errors (Durbin-Watson value $=1.921$ ), normality, homogeneity of variance and linearity were all met.

\section{Discussion}

The first objective of this study was to establish the prevalence of cardiometabolic risks in the study population (schizophrenia spectrum disorders; SSD) as indicated by levels of overweight/obesity, CVD relative risk and presence of MES. Over two-thirds of participants (68\%) were found to have a BMI $\geq 23 \mathrm{~kg} / \mathrm{m}^{2}$ and almost half were centrally obese. Recent estimates have suggested that $39 \%$ of the Hong Kong population has a BMI $\geq 23 \mathrm{~kg} / \mathrm{m}^{2}$ [54] and thus our results indicate 
that the patients in the current study have a $174 \%$ increased risk of being overweight/obese when compared with the general population. An earlier study conducted by Guo et al., in 10 sites across mainland China [55] reported that 54\% of 896 patients with schizophrenia had a BMI $\geq 23 \mathrm{~kg} / \mathrm{m}^{2}$; compared to the $43 \%$ observed in the general Chinese population [56] this equates to an increased risk of $126 \%$. Therefore, it is possible that people with SSD in Hong Kong face greater health inequalities compared to their mainland Chinese counterparts. However, there are numerous potential alternative reasons for these disparities in the results, such as all participants in Guo et al.'s study being prescribed only one type of antipsychotic, and a younger mean age and shorter duration of illness than participants in our current study.

The prevalence of metabolic syndrome (MES) in the current study is $29 \%$ as opposed to $17 \%$ of people in the general Hong Kong population $[57,58]$, suggesting a potential increased risk for MES of $170 \%$ for Chinese people with SSD in Hong Kong. The rate in the current study in randomly selected patients with schizophrenia is lower than the 35\% observed in an earlier Hong Kong study of a convenience sample of people with SMI [59]. The differences between these rates of MES may relate to selection bias in the earlier study [59], in which the non-randomised (convenience) sample were invited to participate by their clinicians on a sequential basis. The variations in rates of MES, levels of obesity and CVD risks across different populations of people with SSD are now well-documented; for example, prevalence rates range between $19 \%$ and $68 \%$ dependent on their country, ethnicity, age, gender, prescribed medications, MES criteria used and duration of illness [4, 60]. Despite these differences, the rates of MES are consistently observed to be elevated in people with SSD when compared with the general population [60].

In the current study over $13 \%$ of patients were found to have a moderate-to-high 10-year CVD risk score (as indicated by $>10 \%$ on the $\mathrm{QRISK}^{\circ} 2$ ), which is considerably higher than the $8 \%$ reported in the large UK derivation cohort of people without SMI but less than the $16 \%$ observed in a community-based UK people with SMI [28]. Similarly, based on a QRISK 2 mean score of $5.28 \%$ in our study and the mean Framingham scores of 8.5\% in American patients with schizophrenia [35] (in spite of different calculation methods for the QRISK ${ }^{\circ} 2$ and Framingham scores), our results suggest that people with SSDs in Hong Kong have a reduced CVD risk compared to the US patients. Perhaps these findings are not surprising given that the CVD rates and life expectancies of the general populations of Hong Kong, the UK and the US vary considerably. Although there are great differences in average life expectancies, it is consistently reported that SSD patients have mortality rates 2-2.5 higher than the general population across international settings, and this has led to calls from the World Health Organisation (WHO) to improve the prevention, identification, assessment and treatment of physical health in people with SSD across the globe [25].

The second objective was to examine potential relationships between prescribed treatment/clinical characteristics, CVD relative risk and health related quality of life (HRQoL). Patients' self-perceived physical HRQoL (PCS) and mental HRQoL (MCS) were both lower than the reported population norms of 50.2 (PCS) and 50.1 (MCS) in Chinese adults in Hong Kong as measured by the SF-12v2 [61]. Therefore, the HRQoL of participants in this study suggests mild-moderate levels of perceived physical and mental health concerns. In line with previous studies we found a relationship between increased BMI and lower physical HRQoL $[12,62]$. In fact, BMI was the strongest predictor of physical HRQoL in the regression model (beta coefficient of -.272, $p=.013$ ), providing further evidence that reductions in BMI may result in improvements in physical HRQoL. However, no direct relationship was observed between mental HRQoL and BMI, which is consistent with results from other studies in people with SMI [12, 14]. It is also interesting to note that although mental HRQoL was not found to directly relate to measures of body weight, the regression model revealed that MCS was a significant explanatory variable for the variance in physical HRQoL subscale scores (beta coefficient of .226, $p=.038$ ). Therefore, the findings highlight a potential significant relationship between perceived mental and physical health, and indicate that weight reduction interventions in this patient group could have the potential to not only enhance physical HRQoL, but also to indirectly improve mental HRQoL of these patients.

Unlike some previous studies [15] which found that reduced HRQoL was associated with metabolic syndrome (MES), we did not find any differences in HRQoL between the patients who did and who did not meet the criteria for MES. Nor did we find any differences in selfreported HRQoL in patients with low/high CVD relative-risk, or identify significant correlations between HRQoL and CVD relative risk. This is an important finding because it may indicate that despite having an elevated risk of CVD or MES, patients do not perceive their physical HRQoL as being low, and thus they may be less likely to actively seek treatment and/or be motivated to make lifestyle changes to improve their physical health state. This reinforces the need to actively promote routine cardiometabolic health assessment for all patients with SSD and share concerns about identified risks using effective psychoeducational interventions. We also did not find any relationship between HRQoL 
and antipsychotic Defined Daily Dose (DDD); which is corresponded with a recent European study of patients with schizophrenia of a similar mean duration of illness [13]. This also could suggest that patients who are receiving higher dosage(s) of antipsychotic do not subjectively recognise any negative impacts on their physical or mental HRQoL, as such they may be less likely to complain about being on higher doses and thus might require appropriate screening and support to recognise potential problems. These observations, in conjunction with evidence suggesting that people with severe mental illness are less likely to receive CVD risk screening tests and are undertreated for CVD [19-21] highlight that mental health care providers need to be particularly vigilant in monitoring the cardiometabolic health of people with schizophrenia, and should proactively promote treatment as appropriate.

A large proportion of patients were prescribed antipsychotic polypharmacy (34\%) and cumulative doses of antipsychotics that are in excess of the WHO DDD (61\%). This is surprising given that with the exception of clozapine augmentation [63-65] there is a lack of convincing evidence that antipsychotic polypharmacy is any more effective than monotherapy in improving psychotic symptoms. This is also concerning because our results show that antipsychotic polypharmacy and a higher DDD was associated with increased CVD relative risk, a greater BMI, higher waist circumference measurement and elevated diastolic blood pressure. These results support the findings from some earlier studies which reported that metabolic changes seen in people with SSD are greater in those prescribed polypharmacy [43] and are often antipsychotic dosedependent [66]. The $34 \%$ of patients prescribed antipsychotic polypharmacy in our study is similar to the median percentage of $32 \%$ for Asian countries reported in a large systematic review which pooled data from 147 studies in four geographical regions [67]. The same review also reports the median percentages of antipsychotic polypharmacy use in Europe (23\%), the US (16\%) and Oceania (16.4\%). Therefore, our study results seem to be consistent with earlier studies suggesting that staff in Asian settings may be more likely to prescribe antipsychotic polypharmacy than their counterparts in other areas of the world. This may highlight a need to review local clinical/prescribing guidelines, critically review patients' prescriptions more frequently or consider staff training requirements. However, this is a cross-sectional study and thus it is impossible to ascertain the appropriateness of the use of more than one antipsychotic drug for participants; it is possible that some polypharmacy prescriptions were made for justifiable reasons, such as the cross-titration of antipsychotic medications, the use of co-prescribed aripiprazole to reduce weight-gain or the augmentation of clozapine to improve symptom response [68].

The regression model in this study also revealed that DDD, clozapine, age and male gender explained almost $40 \%$ of the variance in participants' CVD relative risk. Age was found to be the strongest predictor of CVD relative risk in the regression model (coefficient of -.346 , $p<.001$ ), which could possibly be explained by previous observations that BMI makes a direct contribution towards CVD risk and that antipsychotic-induced weight gain is most marked in younger people [5, 44]. These findings also replicate results from some earlier studies, which indicated that antipsychotics appeared to directly contribute towards CVD risk $[69,70]$ and also that higher doses/polypharmacy are associated with an increased risk of cardiometabolic disorders [38]. In the current study it is difficult to be certain which combinations of antipsychotics present the highest cardiometabolic risks because the duration of exposure to different antipsychotic treatment regimens was not recorded. However, the results certainly seem to highlight that psychiatrists in Hong Kong should aim to proactively minimise the dosages and reduce the number of different antipsychotics that are prescribed for people with SSD.

\section{Study limitations}

This study has a number of methodological limitations which could negatively impact on the validity and generalisability of the findings. Although the participants were randomly selected from the CMHNs caseloads the narrow inclusion criteria used to select the subgroup of patients analysed in the current cross-sectional study may have introduced some selection bias. The 10 year CVD risk estimates should be treated with some caution; despite the QRISK ${ }^{\circ} 2-2015$ calculation tool having an option for Chinese ethnicity, the measure was not validated for Chinese people with SSD living in Hong Kong. We were also unable to objectively verify that the CMHNs adhered to the suggested approach towards waist circumference measurement and missing (or outdated) blood test data were automatically imputed based on age, sex and ethnicity-specific predicted values. Other possible influences on the relationships between antipsychotics and cardiometabolic health (such as levels of medication adherence, duration of exposure to antipsychotic regimens and lifestyle behaviours) are potential unmeasured confounding variables. In addition, the relatively small sample size may have increased the risk of errors and the cross-sectional design is unable to demonstrate causal relationships. Future research should therefore adopt a prospective cohort study design which aims to examine the potential relationships between antipsychotic treatment, 
obesity, HRQoL and CVD risk in a larger sample of randomly selected people with SSD.

\section{Conclusions}

The 10-year CVD relative-risk estimates and high prevalence of obesity/metabolic syndrome suggest that Hong Kong Chinese people with SSD may experience worse cardiometabolic health than the general population. A lower physical HRQoL was associated with a higher BMI, and increased mental HRQoL was found to be related to greater physical HRQoL. Consequently, interventions that reduce obesity in this patient group could directly improve self-perceived physical health quality of life and indirectly enhance mental health quality of life. Clinicians in Hong Kong should consider using routine CVD risk screening for all patients with SSD, implement physical health promotion interventions as appropriate, and be aware that younger male patients who are prescribed higher doses of antipsychotics seem to have the most elevated relative risk of CVD. The relationships observed between cardiometabolic health and polypharmacy/higher doses provide further evidence that antipsychotic treatment regimens are modifiable factors that can contribute towards cardiometabolic risk and hence the subsequent patient mortality rates.

\footnotetext{
Abbreviations

ANOVA: Analysis of variance; BMI: Body mass index; BP: Blood pressure; CHIP: Chinese health improvement profile; CMHN: Community mental health nurses; CPS: Community psychiatric service; CVD: Cardiovascular disease; DDD: Defined daily dose; HDL: High-density lipoprotein; HRQoL: Healthrelated quality of life; ICD10: International classification of diseases version 10; IDF: International Diabetes Federation; LAl: Long-acting intramuscular injections; MCS: Mental component subscale; MES: Metabolic syndrome; PCS: Physical component subscale; RCT: Randomized controlled trial; SF12: 12-item short form survey; SMI: Severe mental illness;

SSD: Schizophrenia-spectrum disorders
}

\section{Acknowledgements}

We are grateful to the nurses and patients that took part in the study and to Mr Ching-chuen Law for his support in data collection.

\section{Funding}

This study was funded via a Hong Kong Polytechnic University Professorial start-up research grant awarded to the first author.

\section{Availability of data and materials}

The data and materials used in this study are available from the first author upon reasonable request via email (dan.bressington@polyu.edu.hk).

\footnotetext{
Authors' contributions

DB designed the study, analysed data, interpreted the data analysis and was the lead for the writing of the article. JM was data collection lead, contributed towards the study design and commented on the final paper. MLT conducted data analysis, helped interpret the data analysis and contributed to the final paper. RG provided advice on study design, advised on data analysis and contributed towards the final paper. EC provided advice on study design, advised on data analysis/interpretation and contributed towards the final paper. WTC provided statistical advice on study design/data analysis strategy and contributed to the final paper. All authors read and approved the final manuscript.
}

\section{Competing interests}

DB has received investigator-initiated research funding from Janssen and Pfizer's UK. RG has received research funding from Pfizer's and Astra Zeneca, and provided consultancy to Janssen, Otsuka, and Eli Lilly. Other authors declare no potential conflicts of interest.

\section{Consent for publication}

Not applicable.

\section{Ethics approval and consent to participate}

The study was approved by the Northern Territories West Cluster Clinical Research Ethics Committee of Hong Kong Hospital Authority (Ref: NTWC/ CREC/1203/13) and The Hong Kong Polytechnic University's Human Subjects Research Ethics Committee (Ref: HSEARS20141202001). All participants provided their written informed consent to participate.

\section{Author details}

${ }^{1}$ School of Nursing, The Hong Kong Polytechnic University, Kowloon, Hong Kong. ${ }^{2}$ Castle Peak Hospital, Tuen Mun, Hong Kong. ${ }^{3}$ Health Services Research Centre, Hamad Medical Corporation, Doha, Qatar.

Received: 16 June 2016 Accepted: 10 November 2016

Published online: 18 November 2016

\section{References}

1. Royal College of Psychiatrists. Positive Cardiometabolic Health Resource. An intervention framework for people experiencing psychosis and schizophrenia. 2014 update. London: Royal College of Psychiatrists; 2014. http://www.rcpsych.ac.uk/pdf/LesterUKAdaptation2014updateA5booklet_ portrait_version.pdf.

2. National Institute for Clinical Excellence. Psychosis and schizophrenia in adults: prevention and management. NICE guidelines [CG178]. 2014.

3. McElroy SL, Guerdjikova A, Kotwal R. Severe mental illness and obesity. In: Bermudes RA, Keck PE, McElroy SL, editors. Managing metabolic abnormalities in the psychiatrically ill: a clinical guide for psychiatrists. Arlington: American Psychiatric Publishing; 2006. p. 55-119.

4. De Hert M, Correll C, Bobes J, et al. Physical illness in patients with severe mental disorders. Prevalence, impact of medications and disparities in health care. World Psychiatry. 2011;10(1):52-77.

5. De Hert M, Detraux J, van Winkel R, Yu W, Correll CU. Metabolic and cardiovascular adverse effects associated with antipsychotic drugs. Nat Rev Endocrinol. 2012;8(2):114-26.

6. Stubbs B, Vancampfort D, De Hert M, Mitchell AJ. The prevalence and predictors of type two diabetes mellitus in people with schizophrenia: a systematic review and comparative meta-analysis. Acta Psychiatr Scand. 2015;132(2):144-57.

7. Foley DL, Morley KI. Systematic review of early cardiometabolic outcomes of the first treated episode of psychosis. Arch Gen Psychiatry. 2011;68(6):609-16

8. Fan Z, Wu Y, Shen J, Ji T, Zhan R. Schizophrenia and the risk of cardiovascular diseases: a meta-analysis of thirteen cohort studies. J Psychiatr Res. 2013;47(11):1549-56.

9. Colton CW, Manderscheid RW. Congruencies in increased mortality rates, years of potential life lost, and causes of death among public mental health clients in eight states. Prev Chronic Dis. 2006;3:1-14.

10. Vancampfort D, Wampers M, Mitchell AJ, Correll CU, Herdt A, Probst M, Hert M. A meta-analysis of cardio-metabolic abnormalities in drug naïve, firstepisode and multi-episode patients with schizophrenia versus general population controls. World Psychiatry. 2013;12(3):240-50.

11. Allison DB, Mackell JA, McDonnell DD. The impact of weight gain on quality of life among persons with schizophrenia. Psychiatr Serv. 2003;54(4):565-7.

12. Faulkner $\mathrm{G}$, Cohn $\mathrm{T}$, Remington $\mathrm{G}$, Irving H. Body mass index, waist circumference and quality of life in individuals with schizophrenia. Schizophr Res. 2007;90(1):174-8.

13. Hansen MV, Hjorth P, Kristiansen CB, Vandborg K, Gustafsson LN, MunkJørgensen P. Reducing cardiovascular risk factors in non-selected outpatients with schizophrenia. Int J Soc Psychiatr. 2016; 62(4):369-76.

14. Strassnig M, Brar JS, Ganguli R. Body mass index and quality of life in communitydwelling patients with schizophrenia. Schizophr Res. 2003;62(1):73-6.

15. McEvoy JP, Meyer JM, Goff DC, Nasrallah HA, Davis SM, Sullivan L, et al. Prevalence of the metabolic syndrome in patients with schizophrenia: baseline results from the Clinical Antipsychotic Trials of Intervention 
Effectiveness (CATIE) Schizophrenia Trial and comparison with national estimates from NHANES III. Schizophr Res. 2005;80:19-32.

16. Medeiros-Ferreira L, Obiols JE, Navarro-Pastor JB, Zúñiga-Lagares A. Metabolic syndrome and health-related quality of life in patients with schizophrenia. Actas Esp Psiquiatr. 2013;41(1):17-26.

17. Harris EC, Barraclough B. Excess mortality of mental disorder. Br J Psychiatry. 1998;173:1 1e53.

18. Lahti M, Tiihonen J, Wildgust $H$, Beary M, Hodgson R, Kajantie E, et al. Cardiovascular morbidity, mortality and pharmacotherapy in patients with schizophrenia. Psychol Med. 2012;12:1e11.

19. Mitchell AJ, Lawrence D. Revascularisation and mortality rates following acute coronary syndromes in people with severe mental illness: comparative meta-analysis. Br J Psychiatry. 2011;198:434-41.

20. Druss BG, Bradford WD, Rosenheck RA, Radford MJ, Krumholz HM. Quality of medical care and excess mortality in older patients with mental disorders. Arch Gen Psychiatry. 2001;58:565-72.

21. Hippisley-Cox J, Parker C, Coupland C, Vinogradova Y. Inequalities in the primary care of patients with coronary heart disease and serious mental health problems: a cross-sectional study. Heart. 2007:93:1256-62.

22. Osborn DP, Nazareth I, King MB. Risk for coronary heart disease in people with severe mental illness Cross-sectional comparative study in primary care. Br J Psychiatry. 2006;188(3):271-7.

23. National Collaborating Centre for Mental Health. The NICE guideline on core interventions in the treatment and management of schizophrenia in adults in primary and secondary care CG82. London: The British Psychological Society and The Royal College of Psychiatrists; 2010.

24. De Hert M, Vancampfort D, Correll CU, Mercken V, Peuskens J, Sweers K, Mitchell AJ. Guidelines for screening and monitoring of cardiometabolic risk in schizophrenia: systematic evaluation. Br J Psychiatry. 2011;199(2):99-105.

25. World Health Organization. Comprehensive Mental Health Action Plan 2013-2020. Geneva: World Health Organization; 2013. Available at http:// apps.who.int/gb/ebwha/pdf_files/WHA66/A66_R8-en.pdf.

26. National Cholesterol Education Program Expert Panel. Third Report of the National Cholesterol Education Program (NCEP) Expert Panel on Detection, Evaluation, and Treatment of High Blood Cholesterol in Adults (Adult Treatment Panel III) final report. Circulation. 2002:106:3143-421.

27. Hippisley-Cox J, Coupland C, Vinogradova Y, Robson J, Minhas R, Sheikh A, Brindle P. Predicting cardiovascular risk in England and Wales: prospective derivation and validation of QRISK2. Br Med J. 2008;336(7659):1475-82.

28. Hippisley-Cox J, Coupland C. Severe Mental IIIness and Cardiovascular Risk, Report to West London Mental Health Trust. 2012. Ref: Q70REC 11/EM/ 20345. Version $1.2 ; 17 / 07 / 2012$

29. Wilson PWF, Castelli WP, Kannel WB. Coronary risk prediction in adults: the Framingham Heart Study. Am J Cardiol. 1987;59:91-4.

30. Yeomans D, Dale K, Beedle K. Systematic computerised cardiovascular health screening for people with severe mental illness. Psychiatr Bull. 2014;38(6):280-4.

31. Tay $Y H$, Nurjono M, Lee J. Increased Framingham 10-year CVD risk in Chinese patients with schizophrenia. Schizophr Res. 2013;147(1):187-92.

32. Robson D, Gray R. Serious mental illness and physical health problems: a discussion paper. Int I Nurs Stud. 2007:44:457-66.

33. Emul M, Kalelioglu T. Etiology of cardiovascular disease in patients with schizophrenia: current perspectives. Neuropsychiatr Dis Treat. 2015;11:2493.

34. Correll CU, Detraux J, De Lepeleire J, De Hert M. Effects of antipsychotics, antidepressants and mood stabilizers on risk for physical diseases in people with schizophrenia, depression and bipolar disorder. World Psychiatry. 2015; 14:119-36.

35. Daumit GL, Dickerson FB, Wang NY, Dalcin A, Jerome GJ, Anderson CA, Appel LJ. A behavioral weight-loss intervention in persons with serious mental illness. N Engl J Med. 2013;368(17):1594-602.

36. International Diabetes Federation consensus workshop: The IDF consensus worldwide definition of the METABOLIC SYNDROME. International Diabetes Federation; 2006. Available at: [http://www.idf.org/webdata/docs/IDF_Meta_ def_final.pdf].

37. Leucht S, Cipriani A, Spineli L, et al. Comparative efficacy and tolerability of 15 antipsychotic drugs in schizophrenia: a multiple-treatments metaanalysis. Lancet. 2013;382:951-62.

38. Ganguly R, Kotzan JA, Miller LS, Kennedy K, Martin B. Prevalence, trends, and factors associated with antipsychotic polypharmacy among Medicaid-eligible schizophrenia patients, 1998-2000. J Clin Psychiatry. 2004;65(10):1-12.

39. Weinmann S, Read J, Aderhold V. Influence of antipsychotics on mortality in schizophrenia: systematic review. Schizophr Res. 2009;113(1):1-11.
40. Baxter A, Harris M, Khatib Y, Brugha et al. Reducing excess mortality due to chronic disease in people with severe mental illness: meta-review of health interventions. Br J Psychiatry. 2016;1-8. doi: 10.1192/bjp.bp.115.163170

41. Taylor D. Antipsychotic polypharmacy-confusion reigns. Psychiatrist. 2010;34(2):41-3.

42. Thongsai S, Gray R, Bressington D. The physical health of people with schizophrenia in Asia: baseline findings from a physical health check programme. J Psychiatr Ment Health Nurs. 2016. doi: 10.1111/jpm.12300

43. Correll CU, Frederickson AM, Kane JM, Manu P. Does antipsychotic polypharmacy increase the risk for metabolic syndrome? Schizophr Res. 2007;89(1):91-100.

44. Maayan L, Correll CU. Weight gain and metabolic risks associated with antipsychotic medications in children and adolescents. J Child Adolesc Psychopharmacol. 2011;21(6):517-35.

45. Von Elm E, Altman DG, Egger M, Pocock SJ, Gøtzsche PC, Vandenbroucke JP, Strobe Initiative. The Strengthening the Reporting of Observational Studies in Epidemiology (STROBE) statement: guidelines for reporting observational studies. Prev Med. 2007:45(4):247-51.

46. Nose M, Tansella M, Thornicroft G, Schene A, Becker T, Veronese A, Barbui C. Is the Defined Daily Dose system a reliable tool for standardizing antipsychotic dosages? Int Clin Psychopharmacol. 2008;23(5):287-90.

47. WHO Collaborating Centre for Drug Statistics Methodology. Guidelines for ATC classification and DDD assignment. WHO Collaborating Centre for Drug Statistics Methodology, Oslo, Norway; 2013. ISBN 978-82-8082-525-4. Available at: http://www.whocc.no/filearchive/publications/1_ 2013guidelines.pdf.

48. Collins GS, Altman DG. An independent and external validation of QRISK2 cardiovascular disease risk score: a prospective open cohort study. BMJ. 2010;340:c2442.

49. Collins GS, Altman DG. Predicting the 10 year risk of cardiovascular disease in the United Kingdom: independent and external validation of an updated version of QRISK2. BMJ. 2012;344:e4181.

50. Mayor S. Doctors no longer have to use Framingham equation to assess heart disease risk, NICE says. BMJ. 2010;340:C1774.

51. Ware Jr JE, Kosinski M, Keller SD. A 12-Item Short-Form Health Survey: construction of scales and preliminary tests of reliability and validity. Med Care. 1996:34(3):220-33.

52. Ware Jr JE, Kosinski M, Bayliss MS, McHorney CA, Rogers WH, Raczek A. Comparison of methods for the scoring and statistical analysis of SF-36 health profile and summary measures: summary of results from the Medical Outcomes Study. Medical care; 1995. AS264-279.

53. Lam ET, Lam CL, Fong DY, Huang WW. Is the SF-12 version 2 Health Survey a valid and equivalent substitute for the SF-36 version 2 Health Survey for the Chinese? J Eval Clin Pract. 2013:19(1):200-8.

54. Hong Kong Government (2015). Health Facts of Hong Kong 2015 Edition. http://www.dh.gov.hk/english/statistics/statistics_hs/files/Health_Statistics_ pamphlet_E.pdf. Accessed 11 Jul 2016.

55. Guo X, Zhang Z, Wei Q, Lv H, Wu R, Zhao J. The relationship between obesity and neurocognitive function in Chinese patients with schizophrenia. BMC Psychiatry. 2013;13(1):1.

56. Wang R, Wu MJ, Ma XQ, Zhao YF, Yan XY, Gao QB, He J. Body mass index and health-related quality of life in adults: a population based study in five cities of China. Eur J Public Health. 2012;22(4):497-502.

57. Ko G, Tang J. Metabolic syndrome in the Hong Kong community: the United Christian Nethersole Community Health Service primary healthcare programme 2001-2002. Singapore Med J. 2007:48(12):1111-6.

58. Ko G, Cockram C, Chow C, Yeung V, Chan W, So W, Chan N, Chan J. Metabolic syndrome by the international diabetes federation definition in Hong Kong Chinese. Diabetes Res Clin Pract. 2006;73:58-64.

59. Bressington D, Mui J, Cheung E, Petch J, Clark A, Gray R. The prevalence of metabolic syndrome in people with severe mental illness in the community in Hong Kong. BMC Psychiatry. 2013;13:87. doi:10. 1186/1471-244X-13-87.

60. De Hert M, Schreurs V, Vancampfort D, et al. Metabolic syndrome in people with schizophrenia: a review. World Psychiatry. 2009;8:15-22.

61. Lam CLK, Wong CKH, Lam ETP, Lo YYC, Huang WW. Population norm of Chinese (HK) SF-12 health survey-version 2 of Chinese adults in Hong Kong. Hong Kong Pract. 2010;32:77-86.

62. Meyer JM, Nasrallah HA, McEvoy JP, Goff DC, Davis SM, Chakos M Lieberman JA. The Clinical Antipsychotic Trials of Intervention Effectiveness (CATIE) Schizophrenia Trial: clinical comparison of subgroups with and without the metabolic syndrome. Schizophr Res. 2005;80(1):9-18. 
63. Kadra G, Stewart R, Shetty H, Downs J, MacCabe JH, Taylor D, Hayes RD. Predictors of long-term ( $\geq$ 6months) antipsychotic polypharmacy prescribing in secondary mental healthcare. Schizophr Res, 2016. http://dx. doi.org/10.1016/.schres.2016.04.010. Accessed 12 Jul 2016.

64. American Psychiatric Association -APA. Treatment of Patients With Schizophrenia. Secondth ed. 2004. p. 1-184.

65. Lochmann van Bennekom M, Gijsman H, Zitman F. Antipsychotic polypharmacy in psychotic disorders: a critical review of neurobiology, efficacy, tolerability and cost effectiveness. J Psychopharmacol. 2013;27(4):327-36.

66. van Winkel $R$, De Hert $M$, Wampers $M$, et al. Major changes in glucose metabolism including new-onset diabetes within 3 months after initiation or switch of atypical antipsychotic medication in patients with schizophrenia and schizoaffective disorder. J Clin Psychiatry. 2008;69:472-9.

67. Correll CU, Gallego JA. Antipsychotic polypharmacy: a comprehensive evaluation of relevant correlates of a long-standing clinical practice. Psychiatr Clin N Am. 2012;35(3):661-81.

68. Gallego JA, Nielsen J, De Hert M, Kane JM, Correll CU. Safety and tolerability of antipsychotic polypharmacy. Expert Opin Drug Saf. 2012;11(4):527-42.

69. Scheen AJ, De Hert MA. Abnormal glucose metabolism in patients treated with antipsychotics. Diabetes Metab. 2007;33(3):169-75.

70. Tschoner A, Engl J, Laimer M, Kaser S, Rettenbacher M, Fleischhacker WW, Ebenbichler CF. Metabolic side effects of antipsychotic medication. Int J Clin Pract. 2007;61(8):1356-70.

\section{Submit your next manuscript to BioMed Central and we will help you at every step:}

- We accept pre-submission inquiries

- Our selector tool helps you to find the most relevant journal

- We provide round the clock customer support

- Convenient online submission

- Thorough peer review

- Inclusion in PubMed and all major indexing services

- Maximum visibility for your research

Submit your manuscript at www.biomedcentral.com/submit 